\title{
Neurobeachin Is Essential for Neuromuscular Synaptic Transmission
}

\author{
Yuhua Su, ${ }^{1}$ Rita J. Balice-Gordon, ${ }^{2}$ Darren M. Hess, ${ }^{2}$ Douglas S. Landsman, ${ }^{2}$ Jeremy Minarcik, ${ }^{3,4}$ Jeffrey Golden, ${ }^{3,4}$ \\ Ivy Hurwitz, ${ }^{1}$ Stephen A. Liebhaber, ${ }^{1}$ and Nancy E. Cooke ${ }^{1}$ \\ Departments of ${ }^{1}$ Genetics and Medicine, ${ }^{2}$ Neuroscience, and ${ }^{3}$ Pathology and the ${ }^{4}$ Children's Hospital of Philadelphia, University of Pennsylvania School of \\ Medicine, Philadelphia, Pennsylvania 19104
}

We report a random disruption in the mouse genome that resulted in lethal paralysis in homozygous newborns. The disruption blocked expression of neurobeachin, a protein containing a BEACH (beige and Chediak-Higashi) domain implicated in synaptic vesicle trafficking and an AKAP (A-kinase anchor protein) domain linked to localization of cAMP-dependent protein kinase activity. nbea-null mice demonstrated a complete block of evoked synaptic transmission at neuromuscular junctions, whereas nerve conduction, synaptic structure, and spontaneous synaptic vesicle release were completely normal. These findings support an essential role for neurobeachin in evoked neurotransmitter release at neuromuscular junctions and suggest that it plays an important role in synaptic transmission.

Key words: action potential; axon; neuromuscular; vesicle; synapse; neurobeachin

\section{Introduction}

Neurobeachin is a $327 \mathrm{kDa}$ protein found predominantly in neural tissues. Ultrastructural and biochemical studies localize neurobeachin to membranous structures, including synapses (Wang et al., 2000). On the basis of conserved structural motifs, neurobeachin is classified as a BEACH (beige and Chediak-Higashi) protein and is closely related to the LYST (lysosomal trafficking protein) protein that is mutated in the beige mouse and in the human Chediak-Higashi syndrome (Nagle et al., 1996). Mutations in $\mathrm{BEACH}$ domains have been shown to result in defects in vesicle biogenesis, fusion, fission, and/or trafficking (Karim et al., 1997; Introne et al., 1999; Certain et al., 2000; Ward et al., 2000). In addition to the BEACH motif, neurobeachin also contains a high-affinity binding site for the type II regulatory subunit of protein kinase A (PKA RII) (Wang et al., 2000). This motif designates neurobeachin as a member of the family of AKAPs (Akinase anchor proteins) that mediate the subcellular localization and control protein kinase A activity (Pawson and Scott, 1997). Together, these data suggest that neurobeachin may modulate signal transduction and vesicular trafficking in neurons and other cells.

Approximately $5-10 \%$ of transgene insertion events generated by pronuclear injections result in a recessive phenotype re-

\footnotetext{
Received 0ct. 14, 2003; revised Feb. 4, 2004; accepted Feb. 10, 2004.

This work was supported by National Institutes of Health Grants HD25147 (N.E.C., S.A.L.), NS38517 (R.J.B.-G.), and NS045365 (D.M.H.). We thank Drs. T. Parsons and P. G. Haydon for helpful discussions, Dr. J. Devaux for assistance with sciatic nerve action potential conduction experiments, N. Shah in the Imaging Core in the Department of Pathology at the University of Pennsylvania for assistance in EM studies, Drs. J. Burch and A. Tosolini at the Fox Chase Cancer Center for derivation of a fibroblast cell line from the GH24OB mouse and subsequent FISH analysis, the University of Utah Genomic Center for providing specified genomic clones, the Transgenic \& Chimeric Mouse Core of the University of Pennsylvania, and John MinSok Kim for technical assistance.

Correspondence should be addressed to Dr. Nancy E. Cooke, 752B Clinical Research Building, University of Pennsylvania School of Medicine, 415 Curie Boulevard, Philadelphia, PA 19104-6149. E-mail: necooke@mail.med.upenn.edu. DOI:10.1523/JNEUROSCI.4644-03.2004

Copyright $\odot 2004$ Society for Neuroscience $\quad 0270-6474 / 04 / 243627-10 \$ 15.00 / 0$
}

flecting transgene interference with host gene expression (Palmiter and Brinster, 1986). Transgene-mediated gene disruptions that result in recessive phenotypes can be exploited to discover proteins that have non-redundant functions in embryonic or adult life. In the present study, a non-expressed transgene, randomly inserted at the mouse neurobeachin locus (nbea), resulted in loss of nbea expression. Mice homozygous for this insertion were born alive and were normal in appearance but lacked all spontaneous or evoked movement and experienced a rapid demise marked by cyanosis. Morphological studies showed that skeletal muscle and neuromuscular junctions were normal in nbea-null mice, and electrophysiological studies showed that muscle fiber contractility, spontaneous neurotransmitter release, and action potential conduction were indistinguishable between nbea-null and wild-type littermates. However, nbea-null mice demonstrated a complete block of nerve-evoked synaptic transmission. These data revealed an unexpected and essential role for neurobeachin in synaptic transmission at neuromuscular junctions.

\section{Materials and Methods}

Probes and primers. Genomic and cDNA fragment probes were labeled with $\left[\alpha-{ }^{32} \mathrm{P}\right] \mathrm{dCTP}(10 \mathrm{mCi} / \mathrm{ml}$; Amersham Biosciences, Arlington Heights, IL) by random priming (Boehringer Mannheim, Mannheim, Germany), followed by purification on G50 spin columns. Oligonucleotide primers were $5^{\prime}$ end-labeled with $\left[\gamma^{-}{ }^{32} \mathrm{P}\right]$ ATP using T4 polynucleotide kinase, followed by purification on G25 spin columns. Probes were as follows: $1.37 \mathrm{~kb} h G H-N$ (human growth hormone gene) genomic probe (coordinates, -494 to 876 of the $h G H-N$ gene; the site of transcription initiation is defined as coordinate 0 ) was released by $S m a I$ from the $2.6 \mathrm{f}$ plasmid. The $0.8 \mathrm{~kb} h G H-N$ genomic probe (coordinates, 1856 to 2660 of the $h G H-N$ gene) was a BglII/EcoRI fragment corresponding to the $3^{\prime}$ half of $h G H-N$ released from the same plasmid. The $3^{\prime}$-junction probe was a $4.9 \mathrm{~kb}$ genomic fragment $\left(824-5791 \mathrm{bp} 3^{\prime}\right.$ to the transgene insertion site) released from clone 3'D210B2A by SpeI and XbaI. Addi- 
tional probes were as follows: 160 bp nbea probe 1 (coordinates, 668 to 827 of the nbea mRNA; the cap site is defined as coordinate 0), $190 \mathrm{bp}$ nbea probe 2 (coordinates, 3245 to 3434 of the nbea mRNA), and $360 \mathrm{bp}$ nbea probe 3 (coordinates, 3408 to 3764 of $n b e a$ mRNA). All coordinates for the nbea mRNA are in reference to the nbea mRNA sequence (GenBank accession number Y18276). In each case, the probe was generated by reverse transcription (RT)-PCR, cloned into pGEM-T Easy Vector (Promega, Madison, WI) and released from the vector by EcoRI digestion. Terminal sequences of $9-15$ bases on each probe are derived from the vector cloning sites. The nbea probes 1 and 2 were used for the RNase protection assays.

Genotyping. All mouse work was performed under the authorization and approval of the Institutional Animal Care and Use Committee of the University of Pennsylvania. The GH240B transgenic line was generated as reported previously (Jones et al., 1995). The $h G H$ transgene $(-0.5 h G H)$ corresponds to the native EcoRI fragment containing $500 \mathrm{bp}$ of $5^{\prime}$ flanking region and the entire transcribed region. The embryos from $G H 240 B \times G H 240 B$ heterozygote intercrosses were harvested at the designated days postcoitum and isolated intact from the uterus. The day of vaginal plugging was designated as embryonic day 0.5 (E0.5). Genotypes were determined by dot blots of tail DNA using a $1.37 \mathrm{~kb} h G H-N$ probe and were verified by Southern blot. Southern blot analyses were performed using standard procedures on 7-10 $\mu \mathrm{g}$ of digested genomic DNA with the restriction enzymes noted. DNA cross-linked to Zetabind nylon membranes was hybridized with $1-2 \times 10^{6} \mathrm{cpm} / \mathrm{ml}$ probe $\left(3^{\prime}\right.$-junction probe) at $65^{\circ} \mathrm{C}$ overnight, followed by high-stringency washes and development on XAR-5 film (Eastman Kodak, Rochester, NY).

Analysis of mRNA. The Northern blot (see Fig. 4) (SeeGene, Seoul, Korea) was hybridized with $1-2 \times 10^{6} \mathrm{cpm} / \mathrm{ml}$ nbea probe 3 , followed by high-stringency washes. RT-PCR was performed on $0.5 \mu \mathrm{g}$ of total RNA in all cases. Reverse transcription and subsequent PCR amplification were performed with nbea I, II, or III primers at $60^{\circ} \mathrm{C}$ annealing temperature. The sequences of these primers are as follows: Nbea I $5^{\prime}, 5^{\prime}$-ATCGGACTCATACAGGTCGGC-3'; Nbea I 3', 5' -TCACATCACAGTGCTCCAAAAGC-3'; Nbea II 5', 5'-GTCTGGGTGGACACACTCTCAATAG-3'; Nbea II 3', 5' -TTTCCATTCCTCCTTTTGCTCC-3'; Nbea III 5', 5'-TCGGTGCCGATCCGCAACAT-3'; and Nbea III 3', 5'-CAGGTTGAGCACGGTCTCCA-3'.

After 22 or 30 cycles of PCR, the $\left[\gamma^{-}{ }^{32} \mathrm{P}\right]$ ATP-labeled PCR products were fractionated on $8 \%$ acrylamide gel with urea. RNase protection assays were done with $\left[{ }^{32} \mathrm{P}\right] \mathrm{CTP}$-labeled antisense or sense orientation riboprobes corresponding to nbea probe 1, nbea probe 2, and mouse glyceraldehyde-3-phosphate dehydrogenase (GAPDH) (internal control) (Ambion, Austin, TX). Each probe was generated by in vitro transcription with MAXIscript T7 Kit (Ambion). Brain total RNA $(15 \mu \mathrm{g})$ was incubated with antisense or sense nbea riboprobe and with GAPDH riboprobe at $50^{\circ} \mathrm{C}$ for $14 \mathrm{hr}$. After digestion in RNase Cocktail (Ambion), products were purified and fractionated on $8 \%$ acrylamide- $8 \mathrm{M}$ urea gel. The wild-type mouse RNA sample hybridized with sense probe or tRNA sample hybridized with antisense probe served as negative controls.

Fluorescence in situ hybridization. The metaphase spreads were prepared from the fibroblasts generated from heterozygote embryos (E16.5) of the $G H 240 B$ mouse line. Biotin-labeled $1.37 \mathrm{~kb} h G H-N$ gene probe was hybridized to metaphase spreads (Bell et al., 1995). The hybridization sites were detected by fluorescein isothiocyanate-conjugated avidin. Cyanine 3-labeled painting probe for mouse chromosome 3 was used to confirm the location of the transgene. Chromosomes were counterstained with diamidino-2-phenylindole.

Isolation of junction fragment genomic clones from the $\mathrm{GH} 240 \mathrm{~B}$ line. Tail DNA from a GH240B heterozygote was digested with BglII and fractionated on $1 \%$ low-gelling-temperature agarose (Sea Plaque; FMC, Rockland, ME); gel slices containing DNA of $\sim 5 \mathrm{~kb}$ (for $5^{\prime}$-junction library) and $\sim 7 \mathrm{~kb}$ (for $3^{\prime}$-junction library) were excised, and DNA was recovered by treatment with $\beta$-agaraseI (New England Biolabs, Beverly, MA). The isolated fragments were ligated into BamHI-digested $\lambda$ ZAP Express Vector (Stratagene, La Jolla, CA), and the ligation products were packaged with Gigapack III Gold Packaging Extract (Stratagene). The $5^{\prime}$ and $3^{\prime}$ libraries were screened with $1.37 \mathrm{~kb} h G H-N$ probe or $0.8 \mathrm{~kb} h G H-N$ probe, and positive phage were plaque purified. The $p B K-C M V$ phage- mid vector containing the insert was excised from $\lambda$ ZAP Express Vector, extracted with Plasmid Maxi Kit (Qiagen, Hilden, Germany), and sequenced from the termini with T7 and T3 primers. Sequencing was continued by walking through the region using iterative primers.

Brain sectioning and staining: light microscope and EM studies. The brains of E18.5 embryos were removed and submersion fixed in $4 \%$ paraformaldehyde. After dehydration through graded ethanol and then xylene, the brains were embedded in paraffin and serially sectioned in the coronal plane at $4-5 \mu \mathrm{m}$. Every hundredth section $(400-500 \mu \mathrm{m}$ between sections) was stained with hematoxylin and eosin according to standard protocols (Santi and Golden, 2001). The sections were evaluated on a Nikon (Tokyo, Japan) E400 microscope equipped with a Nikon FDX-35 camera.

Immunostaining of mouse neuromuscular synapses. Diaphragm muscles from E18.5 mice were removed and processed as whole mounts for immunostaining (Gonzalez et al., 1999; O’Malley et al., 1999). After fixation, postsynaptic acetylcholine receptors (AChRs) were labeled with 10 $\mathrm{gm} / \mathrm{ml}$ rhodamine-conjugated bungarotoxin (Molecular Probes, Eugene, OR), motor nerve terminals and axons were labeled using mouse monoclonal anti-neurofilament (SMI 31; Sternberger Monoclonals, Lutherville, MD) and mouse monoclonal anti-synaptic vesicle protein 2 antibodies (Abs) (Developmental Studies Hybridoma Bank, University of Iowa, Iowa City, IA), and Schwann cells were labeled using a rabbit polyclonal anti-S100 Ab (Dako, High Wycombe, UK) and the appropriate fluorescent dye-conjugated secondary antibodies. Immunostained neuromuscular junctions were analyzed by confocal microscopy (using $40 \times, 1.25$ numerical aperture or $100 \times, 1.4$ numerical aperture oil immersion objectives; TCS 4D system; Leica, Nussloch, Germany). Singleplane projections were assembled from stacks of images. Synaptic area was determined from single-plane projections of AChR staining using interactive software (MetaMorph; Universal Imaging Corporation, West Chester, PA).

Electron microscopic analysis of neuromuscular synapses. The diaphragm was dissected, fixed for several hours in $2 \%$ paraformaldehyde and $1 \%$ glutaraldehyde in $0.1 \mathrm{~m}$ phosphate buffer, postfixed in osmium tetroxide, dehydrated with a graded ethanol series, and embedded in Epon 812 (Polysciences, Warrington, PA). Ultrathin cross sections were collected on Formvar-coated slot grids and were stained with uranyl acetate and lead citrate. Sections were examined with a transmission electron microscope. Electron micrographs were digitized, and measurements were made using interactive software (MetaMorph; Universal Imaging Corporation). All studies were performed in the Imaging Core Facility of the University of Pennsylvania.

Electrophysiologic analyses of neuromuscular synaptic transmission. Pregnant female mice were anesthetized by intraperitoneal injection of $0.5 \mathrm{ml}$ of a mixture of $17.4 \mathrm{mg} / \mathrm{ml}$ ketamine and $2.6 \mathrm{mg} / \mathrm{ml}$ xylazine (Phoenix Pharmaceuticals, St. Joseph, MO), and E18.5 embryos were removed and placed on ice. The diaphragm muscle and its innervation were dissected under cold oxygenated $\left(95 \% \mathrm{O}_{2}-5 \% \mathrm{CO}_{2}\right)$ Rees' Ringer's solution (Rees, 1978). All experiments were performed at room temperature. The muscle was pinned in a Sylgard-lined Petri dish and superfused with oxygenated Ringer's solution, and the muscle-nerve sample was placed into a suction electrode. To assess nerve-evoked muscle contractions, the phrenic nerve was placed into a suction electrode and was stimulated with $0.1-0.2 \mathrm{msec}$ duration square pulses delivered at $0.5-20$ $\mathrm{Hz}$. The stimulus voltage was adjusted from $0.1 \mathrm{mV}$ to $10 \mathrm{~V}$, and muscle contractions were visually monitored through a dissecting microscope. To assess muscle fiber electrical excitability, muscle fibers were placed into a suction electrode and were stimulated with $0.5 \mathrm{msec}$ duration square pulses delivered at $0.5-1 \mathrm{~Hz}$. The stimulus voltage was adjusted over a range from $0.5 \mathrm{mV}$ to $10 \mathrm{~V}$, and muscle contractions were visually monitored through a dissecting microscope. To assess action potentials, a 3-4 mm length of the sciatic nerve was dissected from the hindlimb of E18.5 embryos of each genotype and placed into a chamber superfused with oxygenated Ringer's solution. A suction electrode was placed at one end of the nerve for stimulation with square pulses of $0.1 \mathrm{msec}$ duration, $0.05-0.10 \mathrm{mV}$ amplitude. A second suction electrode was placed at the other end to record the resultant compound action potential. To detect spontaneous and evoked neurotransmitter release, skeletal muscle fibers 
were cut at each end to prevent muscle contractions attributable to muscle fiber depolarization (Glavinovic, 1979). Intracellular recordings were performed using glass microelectrodes filled with $3 \mathrm{M} \mathrm{KCl} \mathrm{(20-40} \mathrm{M} \Omega$ resistance). Muscle fibers were impaled within $\sim 20 \mu \mathrm{m}$ of neuromuscular synapses that were visualized using differential interference contrast or polarized light microscopy. Electrical potentials were amplified using an Axoprobe 1A amplifier (Axon Instruments, Foster City, CA), lowpass filtered at $1 \mathrm{kHz}$, and digitized at $10 \mathrm{kHz}$ using an analog-to-digital converter (DigiData; Axon Instruments) and interactive software (Axoscope; Axon Instruments). Muscle fiber resting membrane potential was continuously monitored, and only fibers with resting potentials more hyperpolarized than $-40 \mathrm{mV}$ and in which the resting potential did not change by $>5 \mathrm{mV}$ during the course of the experiment were studied further. This was the minimum resting potential that allowed a sufficient signal-to-noise ratio to detect miniature endplate potentials (mepps). mepps (from 620 to 1150 mepps per muscle fiber) were recorded for 10-20 min, and amplitude and rise time were analyzed using interactive software (MiniAnal; Synaptosoft, Decatur, GA). To characterize nerveevoked endplate potentials, the stimulation voltage to the phrenic nerve was varied from 0.01 to $2.00 \mathrm{~V}$. To assay AChR function, in one experiment, $1 \mathrm{~mm}$ carbachol was applied to muscles, and muscle contractions were visually observed through a dissecting microscope. To determine whether evoked synaptic transmission could be facilitated in the presence of high calcium, in some experiments, nerve stimulation and recordings were performed in the presence of Ringer's solution containing $4 \mathrm{~mm}$ $\mathrm{Ca}^{2+}$ and 2-4 $\mathrm{mm} \mathrm{Mg}^{2+}$ (Kopp et al., 2000). To determine whether evoked synaptic transmission could be facilitated, presynaptic action potentials were lengthened by blocking voltage-gated $\mathrm{K}^{+}$channels to allow more calcium entry (Mallart, 1985). In some experiments, nerve stimulation and recordings were performed in the presence of $2 \mathrm{~mm} \mathrm{3,4-}$ diaminopyridine (Sigma, St. Louis, MO). To determine whether spontaneous release of mepps was facilitated in the presence of hypertonic sucrose, recordings were performed for 2-3 min after the superfusion of Ringer's solution containing 100-500 mOsm sucrose in some experiments (Hubbard et al., 1968). However, the rate of release could not be measured directly because of the difficulty in obtaining stable intracellular recordings during the robust muscle fiber contractions induced by 100-150 mOsm sucrose.

Statistical analyses were performed using Sigma Plot 4.0 (SPSS, Chicago, IL) or Prism (GraphPad Software, San Diego, CA) software. Data are presented as mean \pm SEM (number of junctions per number of mice).

\section{Results}

\section{Insertion of a nonfunctional human genomic fragment in the} mouse genome resulted in recessive postnatal lethality

In the course of studying human growth hormone gene $(h G H)$ expression, a series of control transgenic mouse lines were established using a minimal $h G H$ genomic fragment. This transgene, $-0.5 h G H$, lacks upstream locus control region determinants and is either not expressed or is expressed at only trace levels in the mouse (Jones et al., 1995). In a series of $-0.5 h G H$ transgenic founders, we noted a single mouse that was unusually small. The dwarf phenotype of this mouse line segregated with the $-0.5 h G H$ transgene in multiple generations. Initial analysis of this transgene failed to reveal $h G H$ expression by RT-PCR of pituitary mRNA (Jones et al., 1995), and trace levels of mRNA could only be detected by high cycle number studies (data not shown). The $-0.5 h G H$ transgene insertion appears to cause the dominantly inherited dwarf phenotype via selective inhibition of postnatal pituitary development ( $\mathrm{Su}$ et al., in preparation). Whether the pituitary defect in this line reflects site-specific aberrant transgene expression or reflects haplo-insufficiency of an endogenous interrupted locus (see below) remains to be determined. A detailed analysis of this dwarf phenotype will be reported separately (Y. Su, S. A. Liebhaber, and N. E. Cooke, unpublished observations).

Transgenic mice heterozygous for the GH240B transgene were intercrossed to further explore the genetic basis for the dwarf phenotype. Unexpectedly, multiple crosses failed to generate viable pups homozygous for the transgene insertion. Analyses of timed embryos from the intercrosses of $G H 240 B$ heterozygotes revealed a normal Mendelian frequency of transgene homozygotes $(25 \%)$ throughout embryonic and fetal development and up to the time of birth. Newborn homozygotes identified immediately after birth were normal in body size and morphology, with the exception of an enlargement of the interscapular brown adipose fat depot (Fig. 1A). However, these homozygotes were motionless, failed to react to tail pinch, rapidly became cyanotic, and subsequently expired (Fig. $1 A$ ). In contrast, wild-type and heterozygous littermates appeared normal in all respects. These data indicated that the $G H 240 B$ transgene insertion resulted in a perinatal, recessive-lethal phenotype reflecting an apparent paralysis with a consequent inability to initiate respiration.

\section{The $-0.5 h G H$ transgene interrupted the nbea locus}

The basis of the recessive perinatal lethality in the $G H 240 B$ line was investigated by defining the structure and site of transgene insertion. The $G H 240 B$ insertion site contained five intact and one truncated copies of the $-0.5 h G H$ transgene (Fig. $1 B$ ) and was mapped to mouse chromosome $3 \mathrm{E} 1$ using fluorescence in situ hybridization (FISH) (Fig. 1C). The genomic regions harboring the $5^{\prime}$ - and $3^{\prime}$-junctions of the transgene insertion site were isolated and cloned (Fig. 2A,B). The corresponding DNA sequences were used to identify $5^{\prime}$ - and $3^{\prime}$-junction fragment genomic clones from a wild-type mouse genomic library (clones UUGC1M0175C20 and UUGC1M117G12; University of Utah Genome Center, Salt Lake City, UT) (Fig. 2C). Comparison of the junction fragment sequences with the corresponding native mouse genomic sequences revealed that the transgene array had inserted neatly in the host genome. A BLAST (basic local alignment search tool) search of the mouse genome using the junction fragment sequences gave a single perfect match to intron 1 of the neurobeachin gene (nbea), 3750 bp 3' to its splice donor site. The transcriptional orientation of the $-0.5 h G H$ transgene array was opposite to that of $n b e a$ (Fig. $2 D$ ). The chromosomal map position of the $-0.5 h \mathrm{GH}$ transgene array at mouse chromosome $3 \mathrm{E} 1$ established by FISH (Fig. 1C) agreed with the previously reported map assignment of nbea to the central region of chromosome 3 (Gilbert et al., 1999).

\section{The $-0.5 h G H$ transgene insertion reduced nbea expression to trace levels}

The impact of the $-0.5 h G H$ transgene insertion on $n b e a$ expression was determined. Because nbea mRNA had been reported to be primarily expressed in the CNS (Wang et al., 2000), the initial analysis was performed on brain mRNA. At 22 cycles of RT-PCR, a strong nbea cDNA signal was generated from the wild-type sample, a less intense signal from transgenene heterozygotes, and no signal from homozygotes (Fig. 3, top panels). At a higheramplification cycle number (30 cycles), a faint signal could be detected from homozygotes, whereas the control reaction lacking RT remained negative (data not shown). nbea mRNA levels were confirmed and quantified by an RNase protection assay; the nbea mRNA signal intensity in heterozygotes was $55 \%$ of wild-type levels, and there was no visible signal in the homozygotes (Fig. 3, middle panel). The $-0.5 h G H$ transgenic homozygotes were subsequently denoted "nbea-null" with the caveat that trace levels of nbea mRNA could be detected with very sensitive assays. We concluded from these studies that the transgene insertion in the 
A

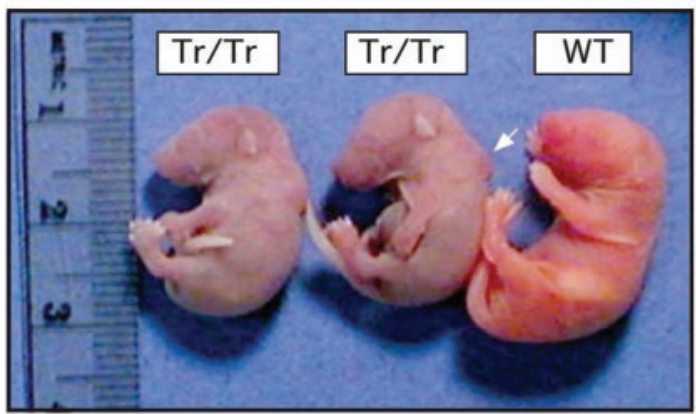

B
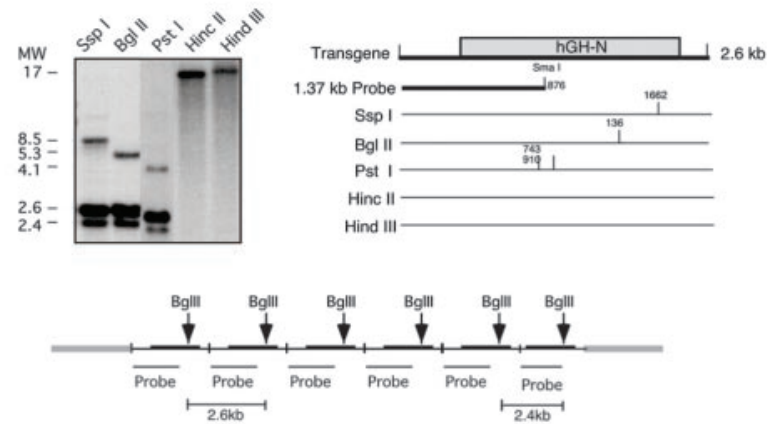

C

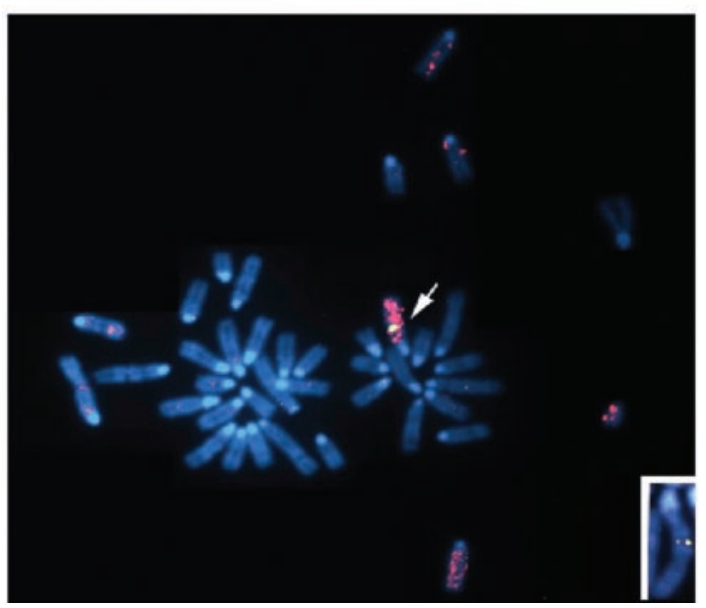

Figure 1. Perinatal lethality of mice homozygous for the transgene insertion. $A$, Newborns from a GH240B intercross. Newborn littermates of a GH240B transgene (Tr) intercross are shown. The two mice on the left are homozygous for the transgene insertion ( $T r / T r)$, and the mouse on the right is a wild-type littermate (WT). The $\mathrm{Tr} / \mathrm{Tr}$ mice lacked spontaneous and stimulated motor activity and died soon after birth. In contrast, the wild-type littermates were active, responsive, and had a pinker complexion. The only visible difference in body structure of the littermates was a dorsal interscapular fat pad in the homozygotes (arrow). The photo in this figure was taken several hours after natural birth. B, Structure of the transgene locus. Genomic DNA from GH240B mouse tissue was digested with the indicated restriction enzymes, and the Southern blot was hybridized with the $1.37 \mathrm{~kb}$ transgene probe (shown below the transgene diagram). The resultant autoradiograph is displayed; the positions of the tandem repeat unit containing the $-0.5 \mathrm{hGH}$ gene ( $2.6 \mathrm{~kb}$ for Sspl and Bg/ll and $2.4 \mathrm{~kb}$ for Pstl), a partially ( $200 \mathrm{bp}$ ) deleted repeat unit $(2.4 \mathrm{~kb}), 5^{\prime}$-junction fragments $(8.5,5.3$, or $4.1 \mathrm{~kb})$, and the high molecular weight (MW) Hincll and Hindlll fragments encompassing the entire insertion site $(\sim 17 \mathrm{~kb})$ are shown. Quantification of repeats in the transgene array was based on comparison of the signal intensity of the internal repeat generated by the head-to-tail tandem array with the intensity of the unique $5^{\prime}$-junction fragment. The presence of a unique set of junction fragments indicated that there was a single insertion site in the genome of the GH24OB mouse. The restriction map of the $h G H-N$ transgene with coordinate numbers is indicated to the right of the autoradiograph. At the bottom is the $\mathrm{Bg} / \mathrm{II}$ map of the overall structure of the transgene insertion. There are five full-length head-to-tail copies of the $-0.5 \mathrm{hGH}$ transgene and a single truncated (2.4 $\mathrm{kb}$ ) copy. C, The transgene locus mapped to mouse chromosome $3 \mathrm{E} 1$ by FISH. FISH analysis was performed on fibroblasts derived from the GH240B line. The study shows a representative
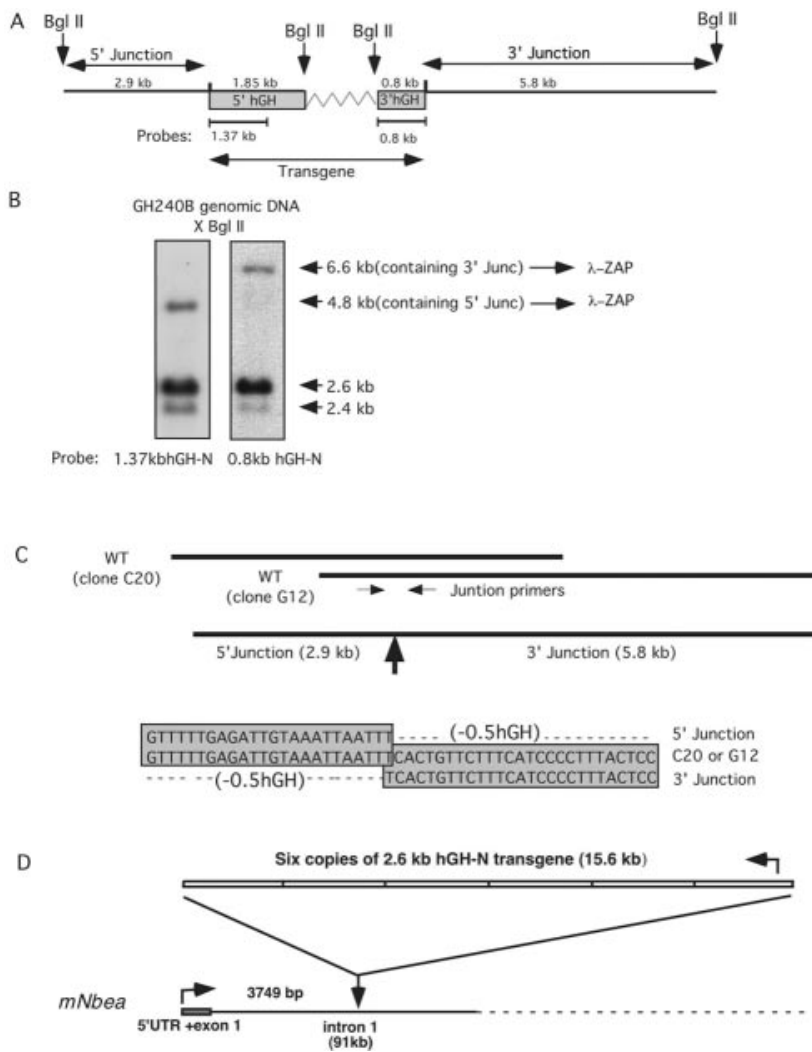

Figure 2. Sequence analysis of the $G H 240 B$ transgene insertion site. A, Map of the $5^{\prime}$ - and $3^{\prime}$-junction fragments of the transgene insertion site. The probes used to identify the $2.9 \mathrm{~kb}$ $B g / l l 5^{\prime}$-junction fragment and the $5.8 \mathrm{~kb}$ Bglll $3^{\prime}$-junction fragment are shown below the diagram. $B$, Isolation of the $5^{\prime}$ - and $3^{\prime}$-junction fragments. Genomic DNA from a GH240B transgenic mouse was digested with Bglll, and the Southern blot was hybridized with $5^{\prime}$ and $3^{\prime}$ probes $(A)$ to identify the $3^{\prime}$ - and $5^{\prime}$-junction fragments. Both probes also hybridized to the six internal tandem repeat fragments (Fig. $1 B$ ). The regions of the gel corresponding to the two junction fragments were excised from a subsequent preparative gel, and the eluted DNA was cloned into $\lambda Z A P$ vectors. The two junction fragments were isolated by recombinant phage screening and were sequenced. C, Alignment of the transgene junction fragments with the wild-type (WT) mouse genomic sequence. The mouse sequences flanking the transgene insertion were determined by sequencing the $5^{\prime}$ and $3^{\prime}$ cloned junction fragments. These mouse genomic sequences were used to identify corresponding wild-type mouse genomic clones (clones (20 and G12). The region corresponding to the transgene insertion site was sequenced from the wild-type clone and aligned with the sequences of the 3 ' - and 5 '-junction fragments (as indicated by the horizontal arrows). Alignment of the wild-type sequences with the sequence at the $5^{\prime}$ - and $3^{\prime}$-junction fragments revealed a clean insertion of the transgene tandem repeat into the host DNA (indicated by the upward arrow). D, The $-0.5 \mathrm{~h} G \mathrm{H}$ transgene is located within intron 1 of the mouse nbea locus. The diagram indicates the position and transcriptional orientation of the transgene insertion relative to the host nbea locus. UTR, Untranslated region.

GH240B line essentially eliminated expression from the host nbea locus.

Wild-type mice express nbea mRNA at highest levels in neural and endocrine tissues

To further define the relationship between transgene insertion and postnatal lethality, the expression profile of the wild-type nbea locus was determined (Fig. 4A). nbea mRNA was readily

$\leftarrow$

metaphase spread. Biotin-labeled $h G H-N$ gene probe was detected by fluorescein isothiocyanate-conjugated avidin (yellow). Cyanine 3-labeled mouse chromosome 3 painting probe identified chromosome 3 (red). The arrow points to the GH24OB transgene locus on the double-stained chromosome 3. The insert shows chromosome 3 hybridized only with the $h G H-N$ probe to allow accurate positioning of the transgene to $3 \mathrm{E} 1$. 

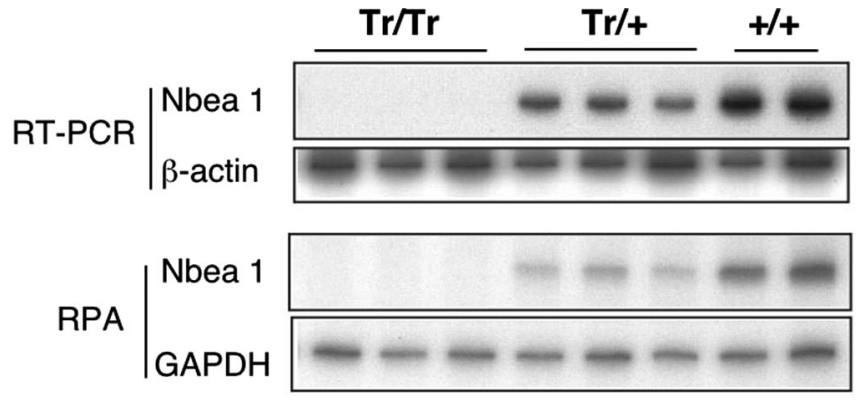

Southern

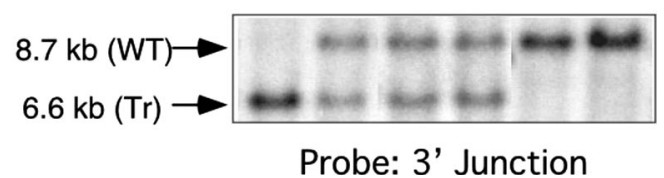

Figure 3. The $-0.5 h G H$ transgene insertion disrupts nbea expression. Top, RT-PCR analysis of nbea mRNA. Embryonic whole-brain RNA was analyzed from E18.5 littermates with the indicated genotypes by RT-PCR using primers to nbea gene sequences (nbea 1 primers). Analysis of the same samples for $\beta$-actin mRNA as a control is shown below. For details, see Materials and Methods. Middle, RNase protection assay (RPA) of nbea mRNA. The same samples used in the top panel were analyzed with a riboprobe (nbea probe I) that extends from exon 1 to exon 2 and bridges the first intron; the size of the protected fragment is appropriate for a spliced nbea mRNA. Signal strength, normalized to the GAPDH mRNA protected signal, was quantified by Phosphorlmager. nbea mRNA levels in the heterozygotes $(\mathrm{Tr} /+)$ were $55 \%$ of wild type $(+$ / + ). Bottom, Genotyping of E18.5 littermates by Southern blot analysis. Tail DNA from embryos corresponding to each of the RNA samples in the top and middle panels was digested with Bglll and analyzed by hybridization with the $3^{\prime}$-junction probe. The expected $8.7 \mathrm{~kb}$ band was seen in the wild type $(+/+)$, the $6.6 \mathrm{~kb}$ fragment diagnostic of the transgene insertion was seen in the homozygotes $(\mathrm{Tr} / \mathrm{Tr})$, and both the wild-type and transgene insertion site bands were observed in the heterozygotes $(\mathrm{Tr} /+)$.

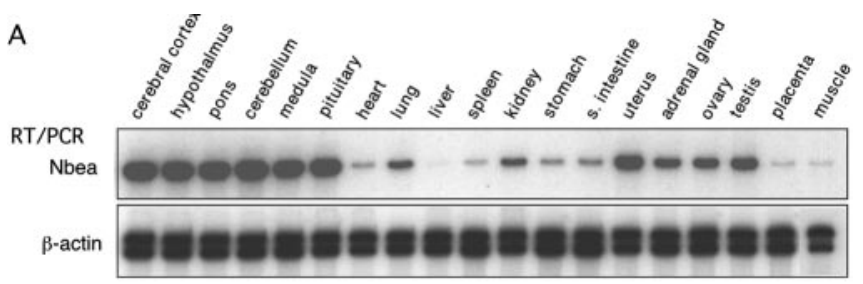

B

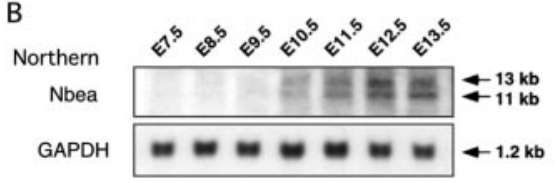

Figure 4. Expression profile of the nbea gene in wild-type mice. A, Tissue survey of nbea mRNA expression. Analysis was performed on mRNA harvested from an adult (3-4 months of age) nbea ${ }^{+/+}$mouse. The RT-PCR primers originated in exons 1 and 2 and bridged the first intron. The RT-PCR was performed exactly as in Figure $3 A$. The size of the amplified fragment is appropriate for a spliced nbea mRNA. The $\beta$-actin mRNA control RT-PCR is shown in the bottom panel. $B$, Normal developmental induction of nbea mRNA expression occurs by E10.5. The Northern blot contains mRNAs harvested from whole wild-type embryos at the indicated times in gestation. The blot was hybridized with an nbea-specific probe and then rehybridized with a GAPDH control probe. The sizes of the corresponding mRNAs are indicated

detected in a number of different tissues. However, the signal intensities were highest in the anterior pituitary and in all regions of the CNS. These results were confirmed by RT-PCR using a second set of primers (data not shown). The developmental progression of nbea expression was assessed by Northern blot (Fig. $4 B)$. The full-length sequence of the nbea mRNA is 10,949 bp. An nbea-hybridizing mRNA band of $11 \mathrm{~kb}$ was first visible in wildtype embryos at E10.5. A slightly larger band of $13 \mathrm{~kb}$ appeared in

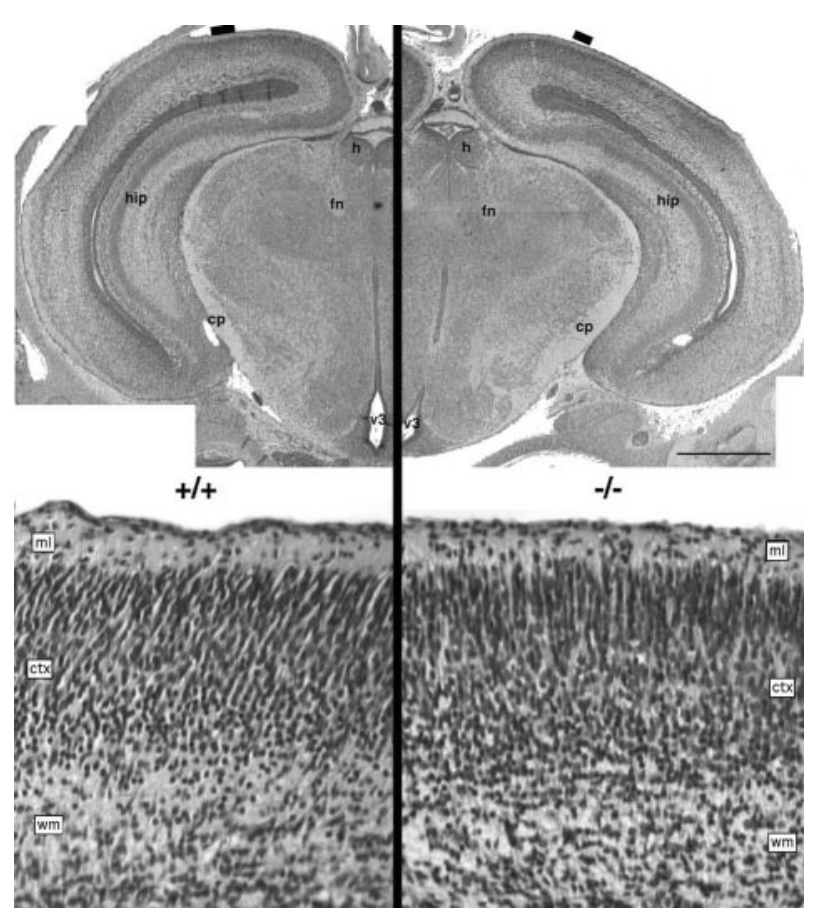

Figure 5. Structural integrity of the nbea-null embryonic brain. Representative coronal hemisection from nbea ${ }^{+/+}$and nbea ${ }^{-/-}$E18.5 littermates stained with hematoxylin and eosin. The sections are taken at the midthalamic level. No structural anomalies were seen in the nbea ${ }^{-1-}$ mouse brains at any level. The image was made as a composite of individual digital images. hip, Hippocampus; $h$, medial habenula; fn, fornix; $c p$, cerebral peduncle; $v 3$, third ventricle; ml, molecular layer; ctx, cortex; wm, white matter. Scale bar, $500 \mu \mathrm{m}$.

parallel. This larger mRNA may represent a differentially spliced nbea transcript, but the structural differences between these two transcripts were not determined. These data show that the wildtype nbea gene is expressed at the highest levels in the CNS and pituitary and that expression is induced at midgestation.

\section{nbea-null mice exhibit normal gross anatomy}

Identification of the interrupted locus as nbea did not clarify the cause of the perinatal lethal phenotype. The anatomy of the newborn $n b e a^{-l-}$ was grossly normal by light microscopic inspection of the liver, lungs, diaphragm, and rib cage (data not shown). Because nbea expression was described as restricted to the brain (Wang et al., 2000) and our RNA analyses confirmed high levels of expression in the CNS, the cytoarchitecture of the brain was analyzed at the gross and light microscopic level. The brains of nbea ${ }^{-1-}$ mice were proportional to body size, indicating that no selective growth advantage or disadvantage was conferred. Coronal sections from multiple levels from olfactory bulbs through the brainstem were made and analyzed from E18.5 $\mathrm{nbea}^{-1-} \mathrm{em}$ bryos (Fig. 5). No abnormalities in the size or cytoarchitecture of gray or white matter were identified in the CNS.

\section{Neuromuscular synapses in nbea-null mice are structurally normal}

Previous work suggesting that neurobeachin is localized to synapses and associated with intracellular membranes and vesicles led to the hypothesis that the lack of movement in newborn nbea $^{-1-}$ pups might reflect a synaptic defect. To evaluate this possibility, we first examined the morphology of neuromuscular junctions. Neuromuscular synapses in the diaphragm muscle from nbea $^{-1-}$ and nbea ${ }^{+/+}$mice were immunostained and imaged using confocal microscopy (O’Malley et al., 1999) (Fig. 6A). 

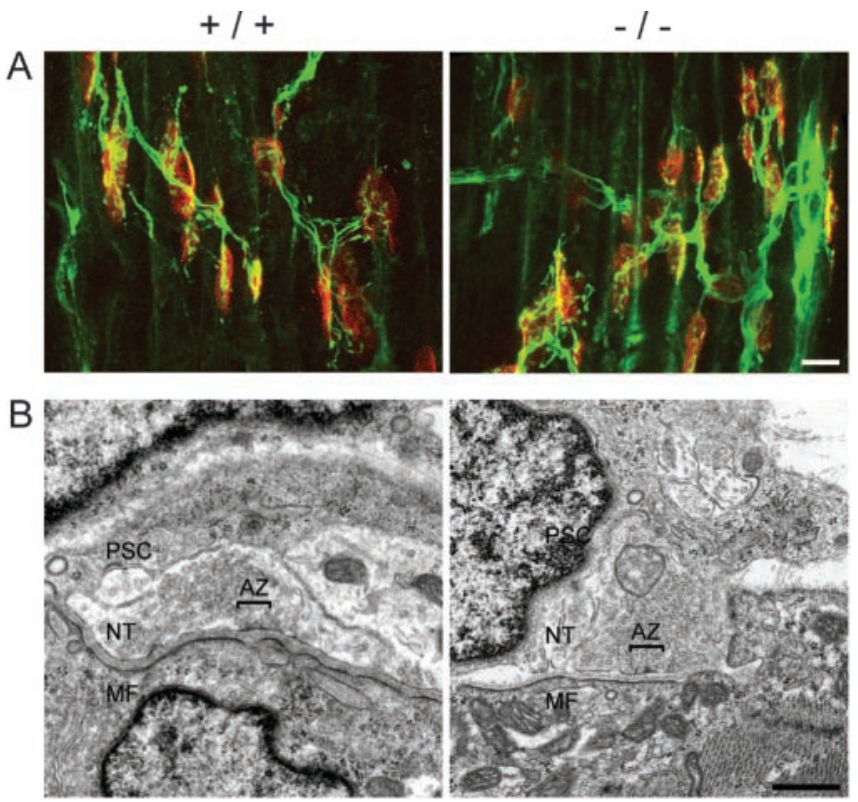

Figure 6. Normal neuromuscular synaptic structure in nbea-null mice. A, Neuromuscular synapses in nbea-null mice are structurally normal at the light microscopic level. Shown is a portion of the diaphragm endplate band isolated from nbea ${ }^{+/+}$(left) and nbea ${ }^{-1-}$ littermates. Immunostained presynaptic motor axons and terminals (green) are apposed to postsynaptic AChR clusters (red). Scale bar, $20 \mu \mathrm{m}$. Each panel is a single-plane projection of a confocal stack of images. Each muscle fiber has a single neuromuscular synapse of normal size (Table 1), showing that neuromuscular synapses develop normally in the absence of neurobeachin. $B$ Neuromuscular synapses in nbea-null mice have normal ultrastructure. Shown are electron micrographs of neuromuscular junctions from nbea ${ }^{+/+}$(left) and nbea ${ }^{-1-}$ littermates. Nerve terminal area, active zone length, and synaptic vesicle number are similar between wild-type and nbea-null synapses (Table 2). Scale bar, $500 \mathrm{~nm}$. PSC, Perisynaptic Schwann cell; NT, nerve terminal; $M F$, muscle fiber; $A Z$, active zone.

Neuromuscular synapses are normally located in an endplate band midway along the length of muscle fibers and contain three cellular components: perisynaptic Schwann cells, presynaptic axons and terminals of spinal motor neurons, and postsynaptic clusters of AChRs (Sanes and Lichtman, 1999). In nbea $^{-1-}$ and $n b_{e a}{ }^{+/+}$mice, immunostaining showed that each muscle fiber was innervated at a single location along its length. At the light microscopic level, neuromuscular synapses from $n b e a^{+/-}$and $\mathrm{nbea}^{-1-}$ mice were similar to those in $n b e a^{+/+}$mice. At individual neuromuscular synapses, presynaptic motor nerve terminals were apposed to postsynaptic AChR clusters (Fig. 6A). Presynaptic motor nerve terminals of $n b_{e a} a^{-1-}$ mice contained neurofilaments and synaptic vesicles, and these were apposed to clusters of AChRs that qualitatively appeared to be stained at intensities similar to those in $n b e a^{+/+}$mice (Fig. $6 A$ ). Synaptic area, measured from postsynaptic AChR cluster area, was similar across genotypes (Table 1). Perisynaptic Schwann cells ensheathed each motor nerve terminal branch and were apposed to presynaptic nerve terminals (data not shown). Thus, at the light microscopic level, the structure of neuromuscular junctions appeared normal in E18.5 nbea-null embryos.

To determine whether neuromuscular synaptic maturation was similar across nbea genotypes, the numbers of presynaptic motor axons innervating muscle fibers were counted from confocal image stacks obtained from E18.5 embryos. Muscle fibers are transiently innervated by more than one motor axon during embryonic and early postnatal development and subsequently lose this multiple innervation via a process of synapse elimination until the adult pattern of single innervation is established (Perso- nius and Balice-Gordon, 2002). Thus, the extent of multiple innervation is one measure of neuromuscular maturation. In muscles from E18.5 wild-type mice, a mean of four axons innervated each muscle fiber, and no differences were observed in the numbers of axons innervating each muscle fiber across nbea genotypes (Table 1). Together, these results suggested that neurobeachin was not required for neuromuscular synapse formation or early maturation.

To determine whether neuromuscular synapses in nbea-null mice were normal at the ultrastructural level, the endplate band was examined using electron microscopy. Neuromuscular synapses in nbea $^{+/+}$E18.5 mice consist of nerve terminal profiles containing mitochondria and clustered synaptic vesicles at electron-dense active zones, apposed to the muscle fiber membrane. A basal lamina is interposed between presynaptic and postsynaptic specializations, and nerve terminals are ensheathed by processes of perisynaptic Schwann cells that sometimes extended fingers into the synaptic cleft. No significant differences were observed between $n b e a^{+/+}$and $n_{b e a^{-1-}}$ mice in the overall localization of these cellular specializations or in nerve terminal cross-sectional area, nerve-muscle contact length, number of active zones per nerve terminal profile, or synaptic vesicle number within 20 or $50 \mathrm{~nm}$ of the active zone (Fig. 6 B; Table 1). These ultrastructural analyses showed that neurobeachin is not required for the assembly of active zones and other cellular features of neuromuscular synapses.

\section{Absence of evoked neuromuscular synaptic transmission in nbea-null mice}

As noted above, nbea $^{-/-}$newborns were motionless and lacked reflexive movement to tail pinch. The lack of movement suggested that neuromuscular synaptic transmission and/or muscle fiber excitability might be defective in these animals. To investigate these possibilities, the diaphragm muscle and its innervation were dissected from E18.5 embryos and subjected to nerve or muscle stimulation. To determine whether muscle fibers were electrically excitable, they were stimulated directly with square pulses of $0.5 \mathrm{msec}$ duration and $0.5 \mathrm{mV}$ to $10 \mathrm{~V}$ amplitude. Muscle contractions were visually monitored through a dissecting microscope. In all embryos of each genotype, muscle fibers contracted robustly when stimulated directly (data not shown). These observations showed that muscle fiber excitability was normal in nbea $^{-1-}$ mice.

To determine whether nerve-evoked muscle contractions were present, the phrenic nerve was stimulated and muscle contractions were visually monitored. In $\mathrm{nbea}^{+/+}$and $n b e a^{+/-}$embryos, muscle fibers in all regions of the muscle twitched robustly. When stimulation frequency was increased to $10-20 \mathrm{~Hz}$, tetanic contractions that were sustained for the duration of nerve stimulation were observed. In marked contrast, nbea ${ }^{-1-}$ embryos failed to respond with twitch or tetanic contractions to any stimulus duration, intensity, or frequency (data not shown). These observations suggested that action potential conduction along axons in the nerve and/or neuromuscular synaptic transmission were disrupted in nbea-null mice.

To determine whether action potentials were conducted normally along axons, a 3-4 mm length of sciatic nerve was dissected from the hindlimb of E18.5 embryos of each genotype and placed into a chamber superfused with oxygenated Ringer's solution. Suction electrodes were placed at each end of the nerve, and one was used to stimulate with square voltage pulses and the other to record the resulting compound action potential. In all nbea genotypes, a robust compound action potential was observed after 
Table 1. Morphometry of neuromuscular junctions in E18.5 nbea mutant mice

\begin{tabular}{|c|c|c|c|c|c|c|}
\hline \multirow[b]{2}{*}{ Genotype } & \multirow[b]{2}{*}{$\begin{array}{l}\text { AChR cluster } \\
\text { area }\left(\mu \mathrm{m}^{2}\right)\end{array}$} & \multirow[b]{2}{*}{$\begin{array}{l}\text { Number of axons } \\
\text { per muscle fiber }\end{array}$} & \multicolumn{4}{|l|}{ Ultrastructure } \\
\hline & & & $\begin{array}{l}\text { Nerve terminal cross-sectional } \\
\text { area }\left(\mu \mathrm{m}^{2}\right)\end{array}$ & $\begin{array}{l}\text { Number of active zones per } \\
\text { nerve terminal profile }\end{array}$ & $\begin{array}{l}\text { Vesicle number within } \\
20 \mathrm{~nm} \text { of active zone }\end{array}$ & $\begin{array}{l}\text { Vesicle number within } \\
50 \mathrm{~nm} \text { of active zone }\end{array}$ \\
\hline$+1+$ & $47 \pm 5$ & $3.1 \pm 0.5$ & $5.2 \pm 0.4(13 / 3)$ & $1.2 \pm 0.2$ & $10 \pm 1.0$ & $24 \pm 1.6$ \\
\hline$+1-$ & $42 \pm 4$ & $2.9 \pm 0.6$ & ND & $1.1 \pm 0.2$ & ND & ND \\
\hline$-1-$ & $43 \pm 7$ & $3.2 \pm 0.5$ & $4.3 \pm 0.7(12 / 2)$ & $1.1 \pm 0.3$ & $9 \pm 0.9$ & $23 \pm 1.3$ \\
\hline
\end{tabular}

Data are shown as mean \pm SEM ( $n$ junctions $/ n$ mice). ND, Not determined. No significant differences were observed across genotypes $(p>0.2 ;$ Student's $t$ test).

A
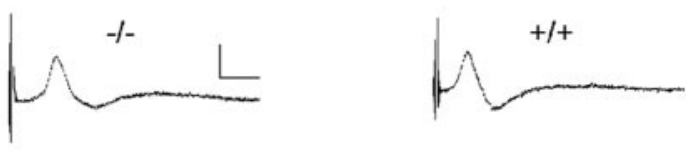

B

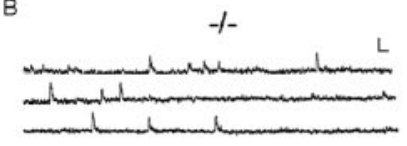

C

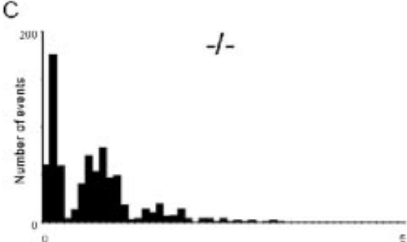

$\mathrm{D}$
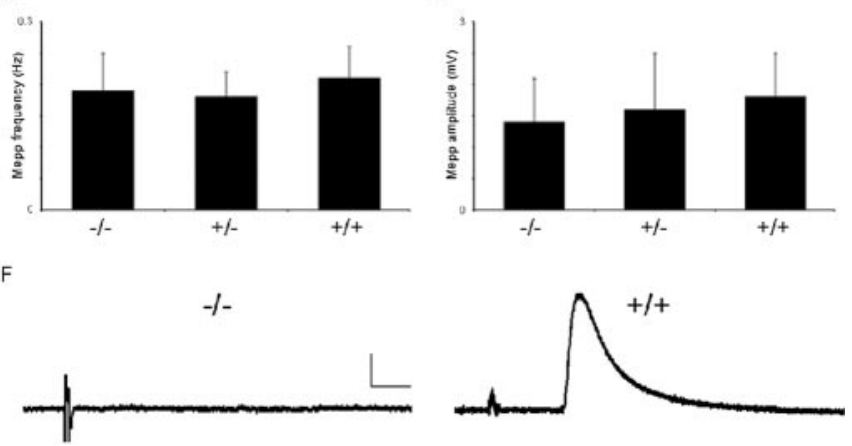

Figure 7. nbea-null mice display normal nerve conduction and spontaneous neurotransmitter release, but neurotransmitter release evoked by nerve stimulation is absent. $A$, Compound action potential recorded from sciatic nerves from $\mathrm{E} 18.5$ nbea $^{-/-}$and $n$ bea ${ }^{+/+}$littermates. Calibration: $1 \mathrm{mV}, 10 \mathrm{mS}$. B, Spontaneous neurotransmitter release (mepps) from a diaphragm muscle fiber from E18.5 nbea $^{-1-}$ and nbea $^{+/+}$littermates. Calibration: $1 \mathrm{mV}, 10 \mathrm{mS}$. C, Distribution of the amplitude of all events from muscle fibers shown in $B$. Distributions are not significantly different; Komolgorov-Smirnoff test; $p=0.425$. In each histogram, the first peak is the distribution of baseline noise in the recordings. $D, E$, mepp frequencies and amplitudes are similar across genotypes (Table 2). Values are shown as mean \pm SEM. F, Nerve stimulation failed to evoke detectable endplate potentials in E18.5 bea $^{-1-}$ mice. Superimposition of five consecutive sweeps of intracellularly recorded membrane potential after muscle nerve stimulation in diaphragm muscle from $n b e a^{-/-}$(left) and nbea ${ }^{+/+}$(right) littermates. Vertical line at left of each trace is nerve stimulation artifact. Calibration: $5 \mathrm{mV}, 2 \mathrm{mS}$.

stimulation (Fig. 7A). Moreover, small compound action potentials were observed when an extracellular electrode was placed in intramuscular nerve branches within the endplate band. These observations indicated that action potential conduction along axons to muscle regions containing synapses was unaffected in nbea $^{-1-}$ mice.

To evaluate neuromuscular synaptic function, intracellular recordings were performed using standard methods (Kopp et al., 2000). Spontaneous mepps were first recorded for 5-10 min. In nbea $^{-1-}$ and nbea $^{+/-}$mice, mepp amplitude, frequency, rise time, and decay time were similar to those observed in nbea $^{+/+}$ mice (Fig. 7B-E; Table 2). The similarity in the mepp amplitudes supported the conclusion from light microscopic analyses that postsynaptic AChR densities were similar across genotypes. These observations demonstrated that spontaneous neurotransmitter release at neuromuscular synapses occurred normally in the absence of neurobeachin.

The function of postsynaptic AChRs was next directly tested. Carbachol (1 mM), an AChR agonist, was applied to nerve-muscle preparations from one nbea ${ }^{+/+}$, one $n b e a^{+/-}$, and two nbea $^{-1-}$ E18.5 embryos, and muscle contractions were monitored. Carbachol induced strong muscle fiber contractions in all genotypes (data not shown). Thus, the absence of evoked epps cannot be attributed to AChR desensitization or other obvious disruption of postsynaptic function.

To characterize nerve-evoked synaptic transmission, the phrenic nerve was stimulated and epps were recorded from diaphragm muscle fibers. In $n b e a^{+/-}$mice, epp amplitude, rise time, decay time, and frequency were similar to that observed in nbea $^{+1+}$ mice (Table 2 ). In $n b e a^{-1-}$ mice, however, no nerveevoked epps were observed at $0.5-1 \mathrm{~Hz}$ stimulation (Fig. $7 F$ ). Thus, the absence of neurobeachin prevented nerve-evoked synaptic transmission.

To characterize the apparent defect in nerve-evoked neurotransmitter release in greater detail, stimulus duration, intensity, and frequency were systematically altered during intracellular recordings. Nerve-evoked epps were absent even when the phrenic nerve was stimulated with short trains of $0.5-1 \mathrm{sec}$ at higher frequency ranging from 5 to $20 \mathrm{~Hz}$. In muscle fibers from nbea $^{+/+}$mice, tetanic stimulation resulted in a transient, approximate twofold increase in mepp frequency that was not observed in nbea $^{-1-}$ mice. No epps were observed when nerve stimulation was repeated in high $\mathrm{Ca}^{2+}$ Ringer's solution or in the presence of 3,4-diaminopyridine to facilitate neurotransmitter release. These observations demonstrated that neurobeachin was required for nerve-evoked presynaptic neurotransmitter release at neuromuscular synapses.

These analyses demonstrated that some aspect of presynaptic neurotransmitter release is compromised in the absence of neurobeachin, but they do not address what steps in neurotransmitter release may be modulated by neurobeachin. To begin to address this issue, the response of muscle fibers to application of 100-500 mOsm hypertonic sucrose solution was determined. Hypertonic sucrose solutions induce the burst-like release of fusion competent vesicles. Application of $100 \mathrm{mOsm}$ sucrose induced robust muscle fiber contractions in nerve-muscle preparations of all nbea genotypes and a twofold to threefold increase in mepp frequency in $n b e a^{+/+}$and $n b e a^{-1-}$ muscle fibers (data not shown). This result, together with the observation that mepp rates were consistent across nbea genotypes in normal Ringer's solution (Table 2), indicated that neurobeachin is unlikely to affect the intrinsic competency of neurotransmitter-containing vesicles for release. Together, these analyses suggest that the ab- 
Table 2. Neuromuscular synaptic transmission in nbea-null mice

\begin{tabular}{|c|c|c|c|c|c|c|}
\hline Genotype & $\begin{array}{l}\text { Resting potential } \\
(\mathrm{mV})\end{array}$ & $\begin{array}{l}\text { mepp } \\
\text { amplitude (mV) }\end{array}$ & $\begin{array}{l}\text { mepp rise time } \\
\text { decay time (msec) }\end{array}$ & mepp frequency $(\mathrm{Hz})$ & $\begin{array}{l}\text { epp amplitude } \\
\text { (mV) }\end{array}$ & epp rise time \\
\hline $\begin{array}{l}+/+ \\
(8 / 3)\end{array}$ & $-45 \pm 3$ & $1.8 \pm 0.7$ & $\begin{array}{r}5.1 \pm 1.7 \\
11.4 \pm 2.1\end{array}$ & $0.21 \pm 0.05$ & $5.1 \pm 2$ & $4.9 \pm 0.7$ \\
\hline $\begin{array}{l}+/- \\
(13 / 2)\end{array}$ & $-48 \pm 7$ & $1.6 \pm 0.9$ & $\begin{array}{l}5.5 \pm 1.3 \\
9.1 \pm 1.5\end{array}$ & $0.18 \pm 0.04$ & $4.7 \pm 1$ & $5.2 \pm 1.2$ \\
\hline $\begin{array}{l}-/- \\
(13 / 3)\end{array}$ & $-47 \pm 3$ & $1.4 \pm 0.7$ & $\begin{array}{r}5.7 \pm 1.9 \\
12.1 \pm 3.6\end{array}$ & $0.19 \pm 0.06$ & $0 \pm 0$ & Not applicable \\
\hline
\end{tabular}

Data are shown as mean \pm SEM ( $n$ junctions $/ n$ mice). No significant difference was observed across genotype $(p>0.2 ;$ Student's $t$ test).

sence of evoked epps in $n b e a^{-1-}$ mice most likely represents a defect in either action potential invasion of nerve terminals or the coupling of action potential invasion to neurotransmitter release.

\section{Discussion}

We report a random transgene insertion in the mouse genome that resulted in a recessive-lethal phenotype. Mice homozygous for this insertion event appeared to develop normally in utero but lacked spontaneous or evoked movements and died immediately after birth from an apparent inability to initiate respiration. The transgene insertion was found to block expression of the neurobeachin gene (nbea). Electrophysiological analyses of nbea-null embryos revealed that neurobeachin is an essential component of the presynaptic machinery required for action potential-evoked neurotransmitter release at neuromuscular synapses. The widespread distribution of neurobeachin expression, including particularly high levels in the brain, suggested that this protein may play an important role in evoked vesicular release and synaptic function in the CNS.

\section{Neurobeachin structure and function}

Mouse neurobeachin is a large $(327 \mathrm{kDa})$ multidomain cytosolic protein that was initially identified by immunoscreening a chicken brain cDNA expression library with Ab raised against an enriched population of synaptic plasma membranes (Wang et al., 2000). Neurobeachin is highly conserved in avian, mammalian, and invertebrate species (Wang et al., 2000; Jogl et al., 2002). Homologs of neurobeachin have been identified in Drosophila (DAKAP550 protein) (Han et al., 1997; Shamloula et al., 2002) and Caenorhabditis elegans (Open Reading Frame database; CEF10F2.1) (Wilson et al., 1994; Ward et al., 2000). Neurobeachin is most prominently expressed in the CNS (Fig. 4) (Wang et al., 2000). EM studies have sublocalized neurobeachin to the cytoplasmic surfaces of multiple intracellular membranous compartments and to pleomorphic tubulovesicular endomembrane near the trans Golgi stacks (Wang et al., 2000). These localizations suggest that neurobeachin may modulate post-Golgi membrane targeting, vesicle trafficking, and exocytosis.

Neurobeachin is a member of a family of proteins sharing a characteristic C-terminal BEACH-WD40 sequence module. The WD40 module has an established capacity for mediating proteinprotein interactions involved in targeting proteins to subcellular compartments (Neer et al., 1994; Adam-Klages et al., 1996). The adjacent BEACH (Nagle et al., 1996) domain comprises a highly conserved 280 amino acid module that has been implicated in vesicular transport, membrane dynamics, and receptor signaling (Jogl et al., 2002). Crystal structure analysis of the neurobeachin $\mathrm{BEACH}$ domain revealed an adjacent weakly conserved pleckstrin homology (PH) domain (Jogl et al., 2002). The combined $\mathrm{PH}-\mathrm{BEACH}$ motifs may present a single continuous structural unit involved in protein binding. The initial member of the $\mathrm{BEACH}$ family to be described was the lysosomal trafficking reg- ulator LYST. This cytosolic protein is involved in lysosomal biogenesis and is implicated in protein sorting among membranous organelles. The LYST gene is mutated in the beige mouse and in the human Chediak-Higashi syndrome (Nagle et al., 1996). Mutations directly involving the BEACH domain in LYST, as seen in Chediak-Higashi, result in pathologic defects in vesicle biogenesis (Karim et al., 1997; Introne et al., 1999; Certain et al., 2000; Ward et al., 2000). A recent report links a case of sporadic autism to interruption of the nbea locus by a chromosomal translocation. No evaluation of nbea expression was possible in this case, and expression of other genes in the vicinity of the translocation was not determined (Castermans et al., 2003). A search of the literature (Gilbert et al., 1999) failed to reveal any other genetic mutations (mouse or human) that map to the mouse or human nbea loci.

In addition to the contiguous $\mathrm{PH}-\mathrm{BEACH} / \mathrm{WD} 40$ motifs at its $\mathrm{C}$ terminus, neurobeachin also contains a centrally located, highaffinity binding site for PKA RII (Wang et al., 2000). cAMPdependent PKA transduces multiple extracellular signals involved in membrane traffic (Edelman et al., 1987; Taylor et al., 1990). AKAPs bind specific regulatory subunits of PKA (RI or RII) and confine the holoenzyme to discrete locations within the cell (Colledge and Scott, 1999). In this way, PKA is exposed to discrete subcellular cAMP gradients that allow for localized catalytic activation and accurate substrate selection. The 20 amino acid PKA RII binding site in mouse neurobeachin is conserved in the Drosophila neurobeachin homolog (DAKAP550) (Wang et al., 2000). The presence of an A-kinase anchor domain in conjunction with the protein-interaction BEACH domain may allow neurobeachin to play a pivotal role in targeting PKA to specific membranous or vesicular compartments (Colledge and Scott, 1999).

Several lines of evidence support specific roles for PKA-AKAP interactions in synaptic function. Calcium-dependent facilitation of presynaptic acetylcholine release is modulated by PKA activity, and AKAPs have been suggested to modulate presynaptic differentiation and synaptic localization of PKA (Ghirardi et al., 1992; Losavio and Muchnik, 2000; Hirsh and Silinsky, 2002). Intriguingly, RI $\alpha$ is colocalized with synaptophysin to presynaptic vesicles (Perkins et al., 2001). AKAP15, an RII binding protein, targets PKA to calcium channels and has been shown to facilitate voltage-dependent L-type calcium channel function via localized phosphorylation by PKA (Gray et al., 1998). Together with analyses of neurobeachin expression and localization, these studies support the idea that neurobeachin may modulate the targeting and function of PKA in neurons and at synapses.

\section{The role of neurobeachin in neurotransmitter release}

The studies reported here reveal that nbea-null mice suffer from generalized paralysis attributable to a block of evoked synaptic transmission. The complete absence of evoked epps, in conjunction with normal conduction of action potentials along axons 
and within the endplate band, normal spontaneous neurotransmitter release, and normal postsynaptic AChR function, support the conclusion that neurobeachin plays a novel and unanticipated role in nerve-evoked synchronous release of neurotransmitter vesicles from presynaptic terminals.

Recent evidence from a number of genetic models suggests that spontaneous and evoked neurotransmitter release can be dissociated to varying degrees, depending on the nature of the molecular defect (Rizo and Sudhof, 2002). Loss of the synaptic vesicle SNARE (soluble $N$-ethyl maleimide sensitive factor adaptor protein receptor) protein synaptobrevin, which mediates vesicle-cell membrane fusion and exocytosis, results in a 10-fold decrease in mepp frequency and a 100-fold decrease in evoked neurotransmitter release (Schoch et al., 2001). Synaptotagminnull mice show a deficit in fast calcium-dependent evoked synaptic transmission, whereas spontaneous release of mepps occurs but is diminished in frequency (Geppert et al., 1994). Similarly, mice null for both complexin isoforms have a complete loss of evoked synaptic transmission but maintain normal spontaneous release of mepps (Reim et al., 2001). Loss of the synaptic plasma membrane proteins SNAP-25 (synaptosome-associated protein of $25 \mathrm{kDa}$ ) and synaptobrevin, thought to be involved in vesicle docking and fusion, both result in a total loss of evoked neurotransmitter release. In the case of SNAP-25, this defect is associated with a paradoxical increase in mepp frequency (Washbourne et al., 2002), whereas in the case of synaptobrevin, mepp frequency is diminished by 75\% (Deitcher et al., 1998). On the other hand, mice lacking a syntaxin-interacting protein such as munc18-1, involved in the early steps of vesicular formation and docking, have a block of both spontaneous and evoked synaptic transmission (Verhage et al., 2000). The complete block of evoked synaptic transmission despite normal spontaneous release observed in nbea-null mice suggests that neurobeachin may function in action potential invasion of the nerve terminal, terminal depolarization or later events, such as calcium entry, that are required for coordinated vesicular release.

The molecular mechanism that links neurobeachin function to evoked synaptic transmission remains unclear. It is possible that action potential invasion of the nerve terminal may be compromised, leading to a block of evoked transmission but leaving spontaneous release unaffected. Although the presence of normal action potential conduction along axons in the sciatic nerve and within intramuscular nerve branches makes this unlikely, experiments at synapses more amenable to focal extracellular recording of action potentials will be required to address this possibility. Alternatively, the loss of neurobeachin may directly or indirectly affect calcium channels, decreasing calcium influx into the nerve terminal after depolarization. Whereas tetanic nerve stimulation resulted in a transient, approximate twofold increase in mepp frequency in $\mathrm{nbea}^{+/+}$mice, no increase was observed in $n b e a^{-/-}$ mice, consistent with this possibility. Phosphorylation of N-type calcium channels inhibits interactions with SNARE proteins, and altering the interaction between presynaptic calcium channels and synaptic proteins has been shown to decrease synaptic transmission (Rettig et al., 1997; Yokoyama et al., 1997). Finally, neurobeachin may modulate the steps in the synaptic vesicle cycle in which calcium is required to trigger synaptic vesicle fusion (Rizo and Sudhof, 2002). Each of these possibilities is consistent with the observations that the intrinsic release competency of neurotransmitter vesicles was unaffected in the absence of neurobeachin, because mepp rates were identical across nbea genotypes and bursts of mepps were triggered by hyperosmotic sucrose in nbea-null as in wild-type mice. Together, our analyses support the hypothesis that neurobeachin function is localized between action potential invasion of nerve terminals and vesicle fusion.

The robust expression of neurobeachin in the CNS (Wang et al., 2000) (Fig. 4) suggests that it may play a general role in synaptic transmission in addition to its specific role at the neuromuscular junction. It is quite likely, for example, that neurobeachin is involved in neuron-to-neuron transmission. The possibility can be directly tested in future studies. It is also possible that neurobeachin may modulate non-neuronal vesicular trafficking and release. In light of the high-level and widespread expression of neurobeachin in normal embryos, the loss of neurobeachin did not affect the normal development of the CNS or of neuromuscular synapses (Figs. 5, 6). This is, however, consistent with previous observations that evoked synaptic activity is not necessary for presynaptic or postsynaptic differentiation (Verhage et al., 2000), although synaptic activity may be important for later synaptic maintenance (Verstreken and Bellen, 2002).

The analysis of a random transgene insertion has revealed a novel and unanticipated role for neurobeachin in synaptic transmission. Whereas neurobeachin plays an essential role in action potential-evoked neurotransmitter release, it is not required for vesicle fusion per se. Considering that neurobeachin is a PKAanchoring protein with a high affinity for regulatory subunits of PKA, a PKA-dependent mechanism may underlie the defect in evoked neurotransmitter release in neurobeachin mutants. Studies of the role of neurobeachin in these mechanisms at neuromuscular and CNS synapses will be one aspect of future studies.

\section{References}

Adam-Klages S, Adam D, Wiegmann K, Struve S, Kolanus W, SchneiderMergener J, Kronke M (1996) FAN, a novel WD-repeat protein, couples the p55 tumor necrosis factor-receptor to neutral sphingomyelinase. Cell 86:937-947.

Bell DW, Taguchi T, Jenkins NA, Gilbert DJ, Copeland NG, Gilks CB, Zweidler-McKay P, Grimes HL, Tsichlis PN, Testa JR (1995) Chromosomal localization of a gene, GF1, encoding a novel zinc finger protein reveals a new syntenic region between man and rodents. Cytogenet Cell Genet 70:263-267.

Castermans D, Wilquet V, Parthoens E, Huysmans C, Steyaert J, Swinnen L, Fryns JP, Van de Ven W, Devriendt K (2003) The neurobeachin gene is disrupted by a translocation in a patient with idiopathic autism. J Med Genet 40:352-356.

Certain S, Barrat F, Pastural E, Le Deist F, Goyo-Rivas J, Jabado N, Benkerrou M, Seger R, Vilmer E, Beullier G, Schwarz K, Fischer A, de Saint Basile G (2000) Protein truncation test of LYST reveals heterogenous mutations in patients with Chediak-Higashi syndrome. Blood 95:979-983.

Colledge M, Scott JD (1999) AKAPs: from structure to function. Trends Cell Biol 9:216-221.

Deitcher DL, Ueda A, Stewart BA, Burgess RW, Kidokoro Y, Schwarz TL (1998) Distinct requirements for evoked and spontaneous release of neurotransmitter are revealed by mutations in the Drosophila gene neuronalsynaptobrevin. J Neurosci 18:2028-2039.

Edelman AM, Blumenthal DK, Krebs EG (1987) Protein serine/threonine kinases. Annu Rev Biochem 56:567-613.

Geppert M, Goda Y, Hammer RE, Li C, Rosahl TW, Stevens CF, Sudhof TC (1994) Synaptotagmin I: a major $\mathrm{Ca}^{2+}$ sensor for transmitter release at a central synapse. Cell 79:717-727.

Ghirardi M, Braha O, Hochner B, Montarolo PG, Kandel ER, Dale N (1992) Roles of PKA and PKC in facilitation of evoked and spontaneous transmitter release at depressed and nondepressed synapses in Aplysia sensory neurons. Neuron 9:479-489.

Gilbert DJ, Engel H, Wang X, Grzeschik KH, Copeland NG, Jenkins NA, Kilimann MW (1999) The neurobeachin gene (Nbea) identifies a new region of homology between mouse central chromosome 3 and human chromosome 13q13. Mamm Genome 10:1030-1031.

Glavinovic MI (1979) Voltage clamping of unparalysed cut rat diaphragm for study of transmitter release. J Physiol (Lond) 290:467-480. 
Gonzalez SL, Saravia F, Gonzalez Deniselle MC, Lima AE, De Nicola AF (1999) Glucocorticoid regulation of motoneuronal parameters in rats with spinal cord injury. Cell Mol Neurobiol 19:597-611.

Gray PC, Johnson BD, Westenbroek RE, Hays LG, Yates III JR, Scheuer T, Catterall WA, Murphy BJ (1998) Primary structure and function of an A kinase anchoring protein associated with calcium channels. Neuron 20:1017-1026.

Han JD, Baker NE, Rubin CS (1997) Molecular characterization of a novel A kinase anchor protein from Drosophila melanogaster. J Biol Chem 272:26611-26619.

Hirsh JK, Silinsky EM (2002) Inhibition of spontaneous acetylcholine secretion by 2-chloroadenosine as revealed by a protein kinase inhibitor at the mouse neuromuscular junction. Br J Pharmacol 135:1897-1902.

Hubbard JI, Jones SF, Landau EM (1968) An examination of the effects of osmotic pressure changes upon transmitter release from mammalian motor nerve terminals. J Physiol (Lond) 197:639-657.

Introne W, Boissy RE, Gahl WA (1999) Clinical, molecular, and cell biological aspects of Chediak-Higashi syndrome. Mol Genet Metab 68:283-303.

Jogl G, Shen Y, Gebauer D, Li J, Wiegmann K, Kashkar H, Kronke M, Tong L (2002) Crystal structure of the BEACH domain reveals an unusual fold and extensive association with a novel $\mathrm{PH}$ domain. EMBO J 21:4785-4795.

Jones BK, Monks BR, Liebhaber SA, Cooke NE (1995) The human growth hormone gene is regulated by a multicomponent locus control region. Mol Cell Biol 15:7010-7021.

Karim MA, Nagle DL, Kandil HH, Burger J, Moore KJ, Spritz RA (1997) Mutations in the Chediak-Higashi syndrome gene (CHS1) indicate requirement for the complete 3801 amino acid CHS protein. Hum Mol Genet 6:1087-1089.

Kopp DM, Perkel DJ, Balice-Gordon RJ (2000) Disparity in neurotransmitter release probability among competing inputs during neuromuscular synapse elimination. J Neurosci 20:8771-8779.

Losavio A, Muchnik S (2000) Facilitation of spontaneous acetylcholine release induced by activation of cAMP in rat neuromuscular junctions. Life Sci 66:2543-2556.

Mallart A (1985) Electric current flow inside perineurial sheaths of mouse motor nerves. J Physiol (Lond) 368:565-575

Nagle DL, Karim MA, Woolf EA, Holmgren L, Bork P, Misumi DJ, McGrail SH, Dussault Jr BJ, Perou CM, Boissy RE, Duyk GM, Spritz RA, Moore KJ (1996) Identification and mutation analysis of the complete gene for Chediak-Higashi syndrome. Nat Genet 14:307-311.

Neer EJ, Schmidt CJ, Nambudripad R, Smith TF (1994) The ancient regulatory-protein family of WD-repeat proteins. Nature 371:297-300.

O’Malley DM, Burbach BJ, Adams PR (1999) Fluorescent calcium indicators: subcellular behavior and use in confocal imaging. Methods Mol Biol 122:261-303.

Palmiter RD, Brinster RL (1986) Germ-line transformation of mice. Annu Rev Genet 20:465-499.

Pawson T, Scott JD (1997) Signaling through scaffold, anchoring, and adaptor proteins. Science 278:2075-2080.

Perkins GA, Wang L, Huang LJ, Humphries K, Yao VJ, Martone M, Deerinck TJ, Barraclough DM, Violin JD, Smith D, Newton A, Scott JD, Taylor SS, Ellisman MH (2001) PKA, PKC, and AKAP localization in and around the neuromuscular junction. BMC Neurosci 2:17.
Personius KE, Balice-Gordon RJ (2002) Activity-dependent synaptic plasticity: insights from neuromuscular junctions. The Neuroscientist $8: 414-422$

Rees D (1978) A non-phosphate-buffered physiological saline for in vitro electrophysiological studies on the mammalian neuromuscular junction [proceedings]. J Physiol (Lond) 278:8P-9P.

Reim K, Mansour M, Varoqueaux F, McMahon HT, Sudhof TC, Brose N Rosenmund C (2001) Complexins regulate a late step in $\mathrm{Ca}^{2+}$. dependent neurotransmitter release. Cell 104:71-81.

Rettig J, Heinemann C, Ashery U, Sheng ZH, Yokoyama CT, Catterall WA Neher E (1997) Alteration of $\mathrm{Ca}^{2+}$ dependence of neurotransmitter release by disruption of $\mathrm{Ca}^{2+}$ channel/syntaxin interaction. J Neurosci 17:6647-6656.

Rizo J, Sudhof TC (2002) Snares and Munc18 in synaptic vesicle fusion. Nat Rev Neurosci 3:641-653.

Sanes JR, Lichtman JW (1999) Development of the vertebrate neuromuscular junction. Annu Rev Neurosci 22:389-442.

Santi MR, Golden JA (2001) Periventricular heterotopia may result from radial glial fiber disruption. J Neuropathol Exp Neurol 60:856-862.

Schoch S, Deak F, Konigstorfer A, Mozhayeva M, Sara Y, Sudhof TC, Kavalali ET (2001) SNARE function analyzed in synaptobrevin/VAMP knockout mice. Science 294:1117-1122.

Shamloula HK, Mbogho MP, Pimentel AC, Chrzanowska-Lightowlers ZM Hyatt V, Okano H, Venkatesh RT (2002) rugose (rg), a Drosophila A kinase anchor protein, is required for retinal pattern formation and interacts genetically with multiple signaling pathways. Genetics 161:693-710.

Taylor SS, Buechler JA, Yonemoto W (1990) cAMP-dependent protein kinase: framework for a diverse family of regulatory enzymes. Annu Rev Biochem 59:971-1005.

Verhage M, Maia AS, Plomp JJ, Brussaard AB, Heeroma JH, Vermeer H Toonen RF, Hammer RE, van den Berg TK, Missler M, Geuze HJ, Sudhof TC (2000) Synaptic assembly of the brain in the absence of neurotransmitter secretion. Science 287:864-869.

Verstreken P, Bellen HJ (2002) Meaningless minis? Mechanisms of neurotransmitter-receptor clustering. Trends Neurosci 25:383-385.

Wang X, Herberg FW, Laue MM, Wullner C, Hu B, Petrasch-Parwez E, Kilimann MW (2000) Neurobeachin: a protein kinase A-anchoring, beige/Chediak-higashi protein homolog implicated in neuronal membrane traffic. J Neurosci 20:8551-8565.

Ward DM, Griffiths GM, Stinchcombe JC, Kaplan J (2000) Analysis of the lysosomal storage disease Chediak-Higashi syndrome. Traffic 1:816-822.

Washbourne P, Thompson PM, Carta M, Costa ET, Mathews JR, LopezBendito G, Molnar Z, Becher MW, Valenzuela CF, Partridge LD, Wilson MC (2002) Genetic ablation of the t-SNARE SNAP-25 distinguishes mechanisms of neuroexocytosis. Nat Neurosci 5:19-26.

Wilson R, Ainscough R, Anderson K, Baynes C, Berks M, Bonfield J, Burton J Connell M, Copsey T, Cooper J, Coulson A, Craxton M, Dear S, Du Z Durbin R, Favello A, Fraser A, Fulton L, Gardner A, Green P, et al. (1994) 2.2 $\mathrm{Mb}$ of contiguous nucleotide sequence from chromosome III of $C$. elegans. Nature 368:32-38.

Yokoyama CT, Sheng ZH, Catterall WA (1997) Phosphorylation of the synaptic protein interaction site on $\mathrm{N}$-type calcium channels inhibits interactions with SNARE proteins. J Neurosci 17:6929-6938. 